mens, or of photographs of drawings or other illustrations of type specimens or of their parts; to catalogue these and make lists available from time to time; to make and to distribute prints of the photographs for suitable fees to those requesting them; and, when finances permit, to make or arrange to have made illustrations of types for the central file. The sub-section is run on a non-profit basis, and in fact will operate at a financial loss until receipts from the sale of prints cover expenses or until grants are obtained. The chief need at the moment is for negatives or other illustrations for the central file, unpublished illustrations being, of course, the most desirable. At present the headquarters of the sub-section and the central file are in Ottawa, and all correspondence should be addressed to $\mathrm{Mr}$. P. F. Bruggemann, Curator, c/o Division of Entomology, Science Service Building, Ottawa, Ontario.

\section{A Faked Fossil}

IN the Museums Journal, March 1954, Mr. H. F. Whitworth, of the Geological and Mining Museum, Sydney, exposes the faked nature of an insect wing in a specimen of selenite. Presented to the Museum in 1912, this was examined by Dr. R. J. Tillyard, who with some hesitation was eventually convinced of the genuineness of the 'fossil' and stated that it belonged to the Tertiary age and was unlike any living form. $\mathrm{He}$ placed it within the family Tettigoniidae and named it Austrodictya corbouldi. Recently, the specimen has been re-examined and it was seen that the crystal of selenite has been opened by a knife, the wing inserted and the edge of the crystal pounded in an endeavour to hide the crack produced. Experiments showed that the flexible nature of selenite allowed this operation to be carried out easily. The wing has now been identified as the forewing of Terpandrus horridus, a present-day form, commonly known as the great gum-tree grasshopper.

\section{Latin American Research in Parasitology}

THE third report in the series, "Latin American Contributions to Scientific Progress", is entitled "Parasitology 1949-50" (pp. 287; Montevideo : Unesco Science Co-operation Office for Latin America, 1953), the two previous publications being concerned with chemistry and with mathematics, respectively. The object of the series is to make known to a much wider public than at present the contributions that Latin American scientific workers are making in various fields. The present report, which is by Prof. J. E. Mackinnon, in collaboration with Prof. S. B. Pessôa, Prof. F. Pifano and Dr. A. Trejos, is concerned with the publications in the field of parasitology that appeared during the years 1949-50. Parasitology is a field that has close association with other studies such as pathology, hygiene, etc.; but while clinical and surgical references appear in the bibliography, the reviews themselves are concerned almost exclusively with experimental and descriptive parasitology, although a certain amount of attention is given to epidemiology and prophylaxis since they are closely related to the biology of the parasite. The reviews are divided into a series of chapters under the five headings protozoa, helminths, arthropods, fungi and various, occupying pp. 14-250, and the bibliography occupies the remaining thirty-seven pages. There are about eleven hundred references, and from this bibliography the titles of the publications, the names of the workers and their fields of study can be found, all of which is most useful information. The authors are Latin Americans or come from other countries but live and work in institutions in Latin America. Naturally, some publications of importance to Latin America come from European possessions or from Panama, and these have been dealt with in their appropriate places by footnotes and do not appear in the body of the text or in the bibliography. On the whole, the English is good; but there are some slips : for example, "flyes" as the plural of fly, "on account of" instead of "as shown by" and so on.

\section{Diploma in Health Education}

ONE of the greatest handicaps to health education has been the lack of properly qualified people. It is hoped that this weakness will be remedied by the proposal of the Institute of Education (University of London) to offer a comprehensive course in health education. It is intended to give a professional training to doctors, nurses, teachers and others with suitable experience, in the basic disciplines and practice of health education. The course will last a year and lead to a diploma of the Institute. The syllabus will deal with the principles of education; principles of social and preventive medicine, including epidemiology and vital statistics; the history and administration of public health and of education; the scientific bases of health and human behaviour with particular emphasis on heredity and genetics, growth and development, environmental hygiene, and the general principles of the causation, spread and prevention of infective disease; and the prin. ciples, methods and media of health education. Field-work will form a part of the course and visits will be made to illustrate the work of hospitals, clinics, local health authorities, schools, youth clubs and industrial concerns.

From the content of the course it would seem that students who obtain the diploma will be qualified to plan and administer comprehensive health education programmes, as well as having the practical experience of the health teacher. A feature of particular interest is the opportunity of providing a tailor-made syllabus for each student to ensure that those with a medical background devote more time to studying education, and vice versa. Sponsors of the course are the London School of Hygiene and Tropical Medicine, the Institute of Child Health and the Central Council for Health Education.

\section{Auxin and Mushroom Growth}

I. M. Fraser (Austral. J. Biol. Sci., 6, 379 ; 1953) reports that the cultivated mushroom, Psalliota hortensis, var. albida, was unable to grow appreciably on a liquid medium containing only glucose, asparagine and mineral salts. Growth was slightly increased by additions of thiamin and biotin to this medium; but a number of other vitamins were without effect. Indole-3-acetic acid, however, in concentrations of 5-100 mgm./l., produced a very notable increase in growth, particularly with biotin and thiamin present, but only in surface culture. The growth of both floating and submerged inocula was markedly increased by additions of yeast extract, cotton wool extract, or mushroom compost extract, although these did not appear to contain appreciable quantities of indole-3-acetic acid. The fungus grew fairly well on basal medium solidified with agar which had been purified to remove vitamins. Addition of thiamin or biotin did not promote growth. Concentrations of indole-3-acetic acid of 10 and 100 mgm./l. olmost completely prevented initial growth, 